\title{
Automated volumetric analysis for comparison of oral sulfate solution (SUPREP) with established cathartic agents at CT colonography
}

\author{
Peter Bannas $^{1,2}$, Joshua Bakke ${ }^{1}$, James L. Patrick ${ }^{1}$, and Perry J. Pickhardt ${ }^{1}$ \\ ${ }^{1}$ Department of Radiology, University of Wisconsin School of Medicine \& Public Health, Madison, \\ WI, USA \\ ${ }^{2}$ Department of Radiology, University Hospital Hamburg-Eppendorf, Hamburg, Germany
}

\begin{abstract}
Purpose-To objectively compare residual colonic fluid volume and attenuation of oral sulfate solution (OSS) with four different established cathartic regimens using an automated volumetric software tool at CT colonography (CTC).
\end{abstract}

Methods-This HIPAA-compliant study had institutional review board approval. Volumetric analysis of residual contrast-tagged colonic fluid was performed on CTC studies in 263 adults (mean age, 60.1 years; 137M/126F) using an automated volumetric software tool. 23 patients receiving $177 \mathrm{ml}$ OSS (SUPREP; single-bottle purgation) were compared with 60 patients each receiving $45 \mathrm{ml}$ sodium phosphate $(\mathrm{NaP}), 90 \mathrm{ml} \mathrm{NaP}(2 \mathrm{xNaP}), 592 \mathrm{ml}$ (two bottles) magnesium citrate $(\mathrm{MgC})$, and $4000 \mathrm{ml}$ polyethylene glycol (PEG). All patients received oral contrast cleansing after catharsis. Data were analyzed with unpaired $t$ test with Welch correction and $F$ test.

Results-The mean volume of residual colonic fluid was less with OSS (125 $\pm 60 \mathrm{ml})$ than for established cathartic agents: $2 \times \mathrm{NaP}(206 \pm 125 \mathrm{ml},(\mathrm{p}<0.0001), \mathrm{MgC}(184 \pm 125 \mathrm{ml}, \mathrm{p}<0.01)$, PEG $(166 \pm 114 \mathrm{ml}, \mathrm{p}<0.05)$ and $\mathrm{NaP}(165 \pm 135 \mathrm{ml}, \mathrm{p}=0.067)$. Variance of volumes was also significantly lower for OSS (range, $28-251 \mathrm{ml}$ ) than for established agents (range, $4-853 \mathrm{ml}$ ) (all $\mathrm{p}<0.01)$. Mean fluid attenuation was higher with OSS $(956 \pm 168 \mathrm{HU})$ than for established agents (all p<0.05): 2xNaP (455 $\pm 191 \mathrm{HU}), \mathrm{MgC}(691 \pm 154 \mathrm{HU}), \mathrm{NaP}(779 \pm 127 \mathrm{HU})$, and PEG $(843 \pm 193 \mathrm{HU})$.

Conclusions-Automated volumetry allows rapid objective assessment of bowel preparation quality at CTC. Purgation with the novel oral sulfate solution (SUPREP) consistently resulted in less residual colonic fluid and higher fluid attenuation compared with established cathartic regimens.

\section{Keywords}

Bowel preparation; CT colonography; oral sulfate solution; automated volumetry

Corresponding author: Peter Bannas, Department of Radiology, University of Wisconsin School of Medicine \& Public Health, E3/311 Clinical Science Center, 600 Highland Ave., Madison, WI 53792-3252, pbannas@ uwhealth.org. 


\section{INTRODUCTION}

Computed tomography colonography (CTC) has been shown to be an effective tool for colorectal cancer screening [1-5], and could improve overall screening compliance if used alongside optical colonoscopy [6-8]. Current levels of colorectal screening lag behind those of other effective cancer screening tests, as roughly half of individuals older than 50 years of age undergo the recommended screening $[9,10]$. It has been estimated that the attainment of goals for population colorectal cancer screening could save 18,800 lives per year in the U.S. [11]. A primary barrier to achieving optimal screening with colonoscopy in general (optical or virtual) is the aversion of many patients to bowel cleansing $[12,13]$. However, cathartic preparation is required for both optical colonoscopy (OC) and for CTC-based screening with same-day polypectomy [14].

Despite the central importance of colon cleansing for effective polyp detection, there is no standardized use of cathartic agents, with wide variation in preparation strategies [15]. Protocols adhering to either single- or double-dose sodium phosphate have been shown to be effective in colon cleansing at both OC and CTC [16,17], but are now seldom used given the rare but finite risk of acute phosphate nephropathy [18]. Magnesium citrate is now considered a front-line laxative for bowel preparation for CTC [19]. In general, these lowvolume regimens are believed to be superior to high-volume regimens such as polyethylene glycol (PEG) with regard to residual fluid retention, as well as patient compliance and preference $[20,21,17,16]$. However, identification of a cathartic agent that further reduces residual fluid while at the same time retaining high patient compliance would be desirable to further improve diagnostic quality.

A new formulation of low volume oral sulfate solution (OSS; SUPREP) has been recently developed and employed for optical colonoscopy [22]. Sulfate is a poorly absorbed anion and OSS does not alter electrolyte balance [22]. The recommended OSS regimen for OC consists of two $177 \mathrm{ml}$ bottles in a split dose. Together, both administrations provide purgation and result in an adequately cleansed colon, suitable for OC. A recent randomized OC clinical study yielded excellent preparation results using the split-dose OSS regimen with two bottles [23]. We aimed to assess the efficacy of a single bottle of OSS for colonic purgation. We hypothesized that a single bottle of OSS for purgation should suffice for CTC bowel preparation because the ionic iodinated oral contrast (sodium diatrizoate/diatrizoate meglumine) acts as an additional mild cathartic or cleansing agent. If this approach proves to be effective for CTC, it could reduce costs and increase patient compliance.

However, assessment of the efficacy of cathartic agents is often cumbersome and large study cohorts are needed [24,21,19]. We now have access to a fully-automated volumetric CTC software tool that provides exact quantification of the total volume and mean attenuation of the residual colonic fluid. If effective, the use of this automated volumetric quality assessment (QA) software may standardize, simplify, and expedite the process of assuring a standard of quality in CTC. The purpose of this study was to perform an objective comparison of volume and attenuation of residual colonic fluid with four different established cathartic regimens to a single bottle of newer oral sulfate solution (OSS; SUPREP) regimen using an automated volumetric software tool at CTC. 


\section{METHODS}

\section{Study Design}

This retrospective study complied with the Health Insurance and Portability and Accountability Act and was approved by our institutional review board; the need for informed consent was waived. We identified at total of 275 patients that underwent CTC evaluation using a variety of cathartic regimens. Patients were only included in the final analyzes if the entire colon could be processed with the CTC software in terms of calculating the total luminal fluid volume. Cases were excluded when the automated tool did not capture all segments of luminal fluid. Twelve cases (4.4\%) were excluded due to incomplete segmentation of luminal fluid, typically related to decreased attenuation from inadequate tagging. In a total of 263 cases (95.6\%) the CTC software successfully calculated the total residual fluid. We identified 60 consecutive patients that received singledose $(45 \mathrm{ml})$ sodium phosphate $(\mathrm{NaP}), 60$ that received double-dose $(90 \mathrm{ml}) \mathrm{NaP}(2 \mathrm{xNaP})$, 60 that received double-dose $(592 \mathrm{ml})$ magnesium citrate $(\mathrm{MgC})$, and 60 that received $4 \mathrm{~L}$ polyethylene glycol (PEG). These four established cathartic regimens were compared with 23 consecutive patients who received a single bottle $(177 \mathrm{ml})$ of oral sulfate solution (OSS; SUPREP, Braintree Laboratories) for purgation, which were supplied by the company as free samples (see different specific cathartic regimes below). All patients underwent oral contrast tagging/cleansing after the cathartic regimen. The tagging regimen (see below) was identical between the all groups, with the exception of the double-dose NaP group, for which the oral contrast volume was doubled (split-dose regimen). Patients without oral tagging were excluded.

Mean patient age was 60.1 years (range, 45 - 93 years), with 126 women and 137 men. Mean patient body mass index (BMI) was $28.7 \mathrm{~kg} / \mathrm{m}^{2}$ (range, $16.6-52.1 \mathrm{~kg} / \mathrm{m}^{2}$ ). The mean age and sex distribution were similar for the five study groups (Table 1).

\section{Cathartic Regimes}

Starting the day before the scheduled CTC examination, patients were restricted to a clear liquid diet and received two 5-mg bisacodyl tablets, which were taken before 11:00 AM. Three to six hours after the bisacodyl tablets, patients ingested the different cathartic agents. The five regimens were as follows:

- Single-dose $\mathrm{NaP}$ regimen consisted of ingestion of $45 \mathrm{ml}$ of sodium phosphate solution (Phospho-soda, Fleet laboratories, Lynchburg, VA).

- Double-dose $\mathrm{NaP}$ regimen consisted of ingestion 2 x $45 \mathrm{ml}$ phosphate solution (Phospho-soda, Fleet laboratories) divided into two doses separated by 3 hours.

- Double-dose $\mathrm{MgC}$ regimen consisted of ingestion of 2 x $296 \mathrm{ml}$ of magnesium citrate solution (Sun-Mark, San Francisco, CA) divided into two doses separated by 3 hours.

- PEG regimen consisted of ingestion of 4 L PEG solution (GoLYTELY, Braintree Laboratories, Braintree, MA) divided into sixteen $237 \mathrm{ml}$ cups taken every 10 minutes. 
- Single bottle OSS purgation regimen consisted of $177 \mathrm{ml}$ of oral sulfate solution, diluted with $296 \mathrm{ml}$ water before ingestion (SUPREP Bowel Prep Kit, Braintree laboratories, Braintree, MA). One dose of OSS SUPREP consists of sodium sulfate $(17.5 \mathrm{~g})$, magnesium sulfate $(1.6 \mathrm{~g})$, potassium sulfate $(3.1 \mathrm{~g})$, and flavoring agents in aqueous liquid form supplied in a $177 \mathrm{ml}$ plastic bottle.

The evening before CTC all patient groups were also given $250 \mathrm{~mL}$ of (2\%) barium sulfate (Readi-Cat 2; E-Z- EM, Lake Success, NY) to tag residual solid stool and $60 \mathrm{~mL}$ of sodium diatrizoate/diatrizoate meglumine (MD-Gastroview; Mallinckrodt, Hazelwood, MO) to tag residual fluid and provide supplementary tagging. This oral contrast regimen was repeated on the morning of the examination for the double-dose NaP group only.

\section{Colonic Distention and CT Acquisition Protocol}

Automated $\mathrm{CO}_{2}$ delivery (PROTOCO $2 \mathrm{~L}$, Bracco Diagnostics) was used to achieve colonic distention. No spasmolytics were employed. After equilibrium intraluminal pressure was achieved, supine and prone CT image acquisition was performed on 4-64 multi-detector CT scanners (GE Healthcare, Waukesha, WI). Acquisition parameters consisted of 1.25-2.50 mm collimation, 1-2 $\mathrm{mm}$ reconstruction interval, $120 \mathrm{kV}_{\mathrm{p}}$, and tube current modulation (noise index set at 50, 30-300 mA range) or $100 \mathrm{mAs}$.

\section{Data Collection and Analysis}

The total volume and mean attenuation of the residual colonic fluid for each patient were derived using automated quality assessment (QA) software available on a beta version of our CTC software (V3D Colon; Viatronix, Stony Brook, NY). Proper processing required correct centerline generation and colonic segmentation. However, areas of complete collapse were allowed as long as these segments contained no or negligible luminal fluid on visual inspection. In this situation, the software automatically crossed the collapsed segment. The colon segmentation algorithm detects the gas-filled luminal cavity by initial thresholding. After visual confirmation and approval of correct segmentation, the QA software uses a region growing technique to delineate all tagged fluid regions connected to the gas-filled lumen by probing for seed pixels greater than $200 \mathrm{HU}$ along the gravitational direction with defined spatial range constraints. In a final step, the partial volume layer that forms between air and tagged fluid is determined. The processed total colonic lumen consist of gas, tagged fluid, and partial volume layer regions. A median filtering technique is applied to the extracted regions to remove morphological irregularity caused by image noise and artifacts. Voxels in the colon lumen region that are less than $200 \mathrm{HU}$ are labeled as air. Voxels in the colon lumen region that are greater than or equal to $200 \mathrm{HU}$ are labeled as tagged fluid. Gas volume, fluid volume, and average fluid attenuation values are calculated by counting the voxels with selected labels.

We recorded the provided luminal fluid volume and its average attenuation (CT attenuation number in $\mathrm{HU}$ ). The efficiency of the automated fluid detection was verified online on axial two-dimensional CTC image review with and without digital subtraction of the tagged fluid (electronic cleansing). This step confirmed that all residual tagged colonic luminal fluid was captured by the automated volumetric tool. 


\section{Statistical Analyses}

Continuous data were expressed as means with standard deviations. Unpaired $t$ test with the

Welch correction was used to compare fluid volumes and fluid densities between established agents and OSS regime. Fisher's exact test was performed to compare the total numbers of optimal versus suboptimal bowel preparations regarding the total volume of residual fluid. We defined total residual colonic fluid volumes below $200 \mathrm{ml}$ as excellent based on subjective image review. $F$ test was used to compare variances of residual fluid volumes between established agents and OSS. Pearson correlation was obtained between volume and attenuation of residual colonic fluid. Statistical computations were obtained with MedCalc Statistical Software version 12.7.5 (MedCalc Software bvba, Ostend, Belgium). A P value of less than 0.05 indicated a statistically significant difference.

\section{RESULTS}

No significant complications were encountered with any of the CTC bowel preparation regimens in the 263 patients. The automated volumetric CTC software tool successfully calculated the mean volume $(175 \pm 118 \mathrm{ml}$, range $4-853 \mathrm{ml})$ and the attenuation $(715 \pm$ $231 \mathrm{HU}$, range $230-1365 \mathrm{HU}$ ) of the residual colonic fluid in all 263 patients. The automated calculation time for volume and attenuation ranged from 5 to 15 seconds. Importantly, not only large and obvious fluid residues were captured, but also tiny pools of luminal fluid. This was visualized and verified online on axial two-dimensional CTC image review using the built-in digital subtraction tool (Figure 1).

A statistically significant difference $(\mathrm{p}<0.001)$ was observed for the volume of residual colonic fluid between the pooled established cathartic regimens (ie, $2 \times \mathrm{NaP}, \mathrm{MgC}, \mathrm{NaP}$ and PEG) $(180 \pm 121 \mathrm{ml}, \mathrm{n}=240)$ and the OSS regime $(125 \pm 60 \mathrm{ml}, \mathrm{n}=23)$ (Figure 2A). Residual fluid volumes $<200 \mathrm{ml}$ were recorded in $66.3 \%$ (159/240 examinations) following the use of established agents and in $87.0 \%$ (20/23 examinations) following OSS regime ( $\mathrm{p}=0.06)$. The variance of the observed volumes was also significantly higher for the average of the established regimens (range, $4-853 \mathrm{ml}$ ) as compared to OSS (range, $28-251)(\mathrm{p}<0.001)$. The higher variance among the 240 patients receiving established cathartic agents is illustrated by 11 outlier cases (4.6\%) (see Figure 2A, indicated as individual points) with high residual fluid volumes ranging from $440 \mathrm{ml}$ to $853 \mathrm{ml}$.

Likewise, the mean attenuation of the residual fluid was significantly higher $(\mathrm{p}<0.0001)$ in the OSS group ( $956 \pm 167 \mathrm{HU}$ ) compared with the pooled established cathartic regimens (692 $\pm 223 \mathrm{HU}$ ) (Figure 2B). The impact of different volumes and densities of the residual fluid on visual assessment of two-dimensional CTC is exemplified in Figure 3.

Comparison of the individual established cathartic regimens ( $2 \times \mathrm{NaP}, \mathrm{MgC}, \mathrm{NaP}$ and $\mathrm{PEG}$ ) versus SUPRPEP further substantiated the overall superiority of the OSS regimen (Figure 4). Mean residual fluid volume was smallest when using the OSS regimen $(125 \pm 60 \mathrm{ml})$ and significantly lower than with $2 x \mathrm{NaP}$ regimen $(206 \pm 125 \mathrm{ml}), \mathrm{MgC}$ regimen $(184 \pm 125 \mathrm{ml})$ or PEG regimen $(166 \pm 114 \mathrm{ml})(\mathrm{p}<0.0001, \mathrm{p}<0.01$ and $\mathrm{p}<0.05$, respectively). The $\mathrm{NaP}$ regimen also showed a higher residual volume $(165 \pm 135 \mathrm{ml})$ than OSS but without quite reaching a statistically significant difference $(\mathrm{p}=0.067)$ (Figure $4 \mathrm{~A})$. Residual fluid volumes 
$<200 \mathrm{ml}$ were recorded less frequently with the individual established agents, in $55.0 \%$ (27/60 examinations, $\mathrm{p}<0.01$ ) with $2 \mathrm{xNaP}, 68.3 \%$ (41/60 examinations, $\mathrm{p}=0.1$ ) with $\mathrm{MgC}$, $68.3 \%$ (41/60 examinations, $\mathrm{p}=0.1$ ) with PEG, $73.3 \%$ (44/60 examinations, $\mathrm{p}=0.2$ ) with $\mathrm{NaP}$ than as compared to OSS regime with $87 \%$ (20/23 examinations). All individual established regimens ( $2 \mathrm{xNaP}, \mathrm{MgC}, \mathrm{NaP}, \mathrm{PEG}$ ) showed a significant higher variance of residual fluid volume than the novel OSS regime (all $\mathrm{p}<0.01$ ).

The attenuation of the residual fluid for all of the individual established cathartic agents was significantly lower than of OSS regimen. Mean attenuation of colonic fluid for $2 \mathrm{xNaP}$, $\mathrm{MgC}, \mathrm{NaP}$ and PEG was $455 \pm 191 \mathrm{HU}, 691 \pm 154 \mathrm{HU}, 779 \pm 127 \mathrm{HU}$ and $843 \pm 193 \mathrm{HU}$, respectively $(\mathrm{p}<0.0001, \mathrm{p}<0.0001, \mathrm{p}<0.0001$ and $\mathrm{p}=0.012$, respectively)(Figure $3 \mathrm{~B})$. The volume of the residual colonic fluid was negatively correlated with fluid attenuation values: $\mathrm{r}=-0.262(\mathrm{p}<0.0001)$ across all the different cathartic regimens. As residual fluid volume decreases, the degree of fluid attenuation generally increases. The correlation is plotted in Figure 5.

\section{DISCUSSION}

With the use of an automated QA software tool that rapidly and objectively determines the volume and attenuation of residual colonic fluid at CTC, we have shown that bowel preparation using the novel OSS (SUPREP) regimen is superior to the previously established cathartic agents. The OSS regimen resulted in less residual colonic fluid compared with previous standard regimens using magnesium citrate, sodium phosphate and PEG. In addition, the variance of the residual volume was also significantly lower with the OSS regimen, suggesting a more consistent result. Use of the automated QA software also revealed that as residual fluid volume decreases, the degree of fluid attenuation generally increases.

Minimization of residual luminal fluid produces higher examination quality and therefore likely improves the ability to correctly identify colorectal lesions at CTC [20,15]. This is especially the case when electronic cleansing (digital subtraction) is not employed in order to avoid the often-disturbing artifacts [25,26]. Because only the gas-filled portions of the colon can be evaluated at 3D endoluminal fly-through without electronic cleansing, the amount of residual fluid directly correlates with lesion detection, as evaluation of fluid-filled regions are limited to 2D assessment. In our study the residual volume in the group receiving the OSS regimen $(125 \mathrm{ml})$ was significantly lower (32\% less fluid) than our current default cathartic agent $\mathrm{MgC}(184 \mathrm{ml})$. Whether this statistically significant difference of $59 \mathrm{ml}$ is also clinically relevant would be best evaluated in future prospective studies that also address the rate of polyp detection. We also found only slightly higher residual total volume (10\% more fluid) in the group receiving $\mathrm{MgC}(184 \mathrm{ml})$ as compared to the group receiving the formerly widely used agent $\mathrm{NaP}(165 \mathrm{ml})$. This is in line with a recent study by Borden et al. who found no significant difference of residual fluid volume between the groups receiving $\mathrm{MgC}$ and $\mathrm{NaP}$ regime using a semi-quantitative 4-point scale [19]. 
The attenuation of the residual fluid in the group receiving OSS regimen $(955 \mathrm{HU})$ was significantly higher (28\% higher attenuation) as compared with $\mathrm{MgC}$ (691 HU). Our finding that the currently recommended $\mathrm{MgC}$ regimen leads to a lower residual fluid attenuation of $691 \mathrm{HU}$ as compared with $\mathrm{NaP}(779 \mathrm{HU})$ are also in line with the study by Borden et al. [19], who reported a significantly higher fluid attenuation of $978 \mathrm{HU}$ for $\mathrm{NaP}$ compared with $790 \mathrm{HU}$ for $\mathrm{MgC}$. The offset between the two studies of $\sim 200 \mathrm{HU}$ for $\mathrm{MgC}$ and of $\sim 100 \mathrm{HU}$ for $\mathrm{NaP}$ is likely due to the fact that Borden et al. randomly sampled the attenuation of fluid only in the ascending and descending colon. In contrast, our automated QA software calculated the average attenuation of the total fluid within all colonic segments.

The optimal attenuation of tagged residual fluid for optimal polyp conspicuity depends on the viewing window used for CTC reading as shown in an experimental setting by Slater et al. [27]. Slater et al. recommended changing the window settings contingent on the attenuation value of tagged fluid when one reviews submerged areas to ensure that no polyp is missed. The QA software tool in our study could be further developed and linked with the two-dimensional viewing console for automated setting of the optimal viewing window according to average residual fluid attenuation. Using a viewing window adjusted to attenuation of residual fluid will maximize both detection and measurement accuracy of submerged polyps.

The automated volumetric assessment matches well with previous studies based on semiquantitative assessment of residual fluid volume and attenuation. However, prior subjective reader volume scores and attenuation measurements are considerably more labor intensive $[19,16,20]$. Moreover, using subjective methods that score the percentage of the colonic lumen filled with fluid are prone to error because these scores are highly dependent on the degree of gaseous distension, which can dramatically affect these semi-quantitative readings.

There have been previous efforts to provide automated assessment of colonic distention and/or residual fluid at CTC [28-30]. However, those attempts have provided primarily linear diameter assessment in defined colonic segments and not a true volumetric analysis of the entire colon. Similar to the above-mentioned subjective reading studies, residual fluid was determined by the percentage of colonic surface area covered by fluid, a value that is highly dependent on the overall colonic distension. Using the fully automated volume QA software tool from this study provides data of the total residual colonic fluid volume that is independent of distention. These data are therefore more objective, more robust, less error prone, and also amplify true differences compared with random samples and/or linear measures. Residual fluid volumes $<200 \mathrm{ml}$ were recorded in $66.3 \%$ of patients following the use of established agents and in $87.0 \%$ following OSS regime. The results did not quite reach statistical significance $(\mathrm{p}=0.06)$, however, this is attributed to the smaller cohort of patients with OSS regimen $(\mathrm{n}=23)$.

Our results using a single bottle of SUPREP extend the findings of a recent OC study where a double bottle split-dose regimen of OSS provided superior CTC bowel cleansing compared with a standard regimen [23]. The reason for our excellent results using only a single bottle of OSS is likely due to the additional cleansing provided by the ionic iodinated 
oral contrast (sodium diatrizoate/diatrizoate meglumine). Using a single bottle of low volume OSS taken the evening before CTC increases the safety, reduces the costs and will likely increase patient acceptance and compliance. Our findings suggest that SUPREP purgation with oral contrast cleansing may improve the diagnostic performance for CTC by reducing the volume of residual fluid.

To put our findings into a clinical context, our results support the use of automated QA software tools for quality assessment of CTC. Utilization of such automated software provides useful quality assurance data and may be employed to improve bowel preparation at individual screening sites. The QA software could be used as part of a quality control program to warn of a slow downward drift in examination quality over time and to indicate the need for additional patient education regarding bowel preparation. Moreover, the presented QA software would enable comparison of data sets from different institutions and from different validation trials. This would ensure a level of uniformity and point out deficiencies of a given program.

We acknowledge limitations to our study. We did not assess the effect of fluid volume and attenuation on lesion detection, but this has been repeatedly shown in larger CTC trials. The automated QA software does not provide segmental data and cannot identify and pinpoint areas that are submerged with fluid. Rather, it rapidly and objectively provides total colonic residual fluid volume and attenuation data as an overall assessment. We did not directly compare our automated method with subjective reading of residual fluid volume and attenuation, because these methods are prone to error as discussed above. It is an inherent limitation of the presented QA software that it does not allow for scoring of residual adherent tagged solid stool - separate from the fluid pools. The amount of residual adherent solid stool is another important factor in assessing the fidelity of bowel preparation at CTC, since its presence complicates polyp detection $[31,26,32]$. The QA software tool will have to be developed further and adapted for assessment of residual stool.

In summary, we have found that the automated QA software tool employed in this study provides an objective quality assessment of bowel preparation at CTC, allowing for rapid and reliable comparison between different regimens. Using automated QA software that objectively determines volume and attenuation of residual colonic fluid at CTC revealed that bowel preparation using the novel OSS regimen (SUPREP) is superior to the previously established regimens. Given the low residual volume, OSS is an excellent alternative for bowel preparation and may lead to improved polyp detection.

\section{Acknowledgments}

This research was supported in part by the National Institutes of Health NCI grants 1R01CA144835-01 and 1R01CA169331-01. P.J.P is a consultant for Mindways, Viatronix, and Braintree; and co-founded VirtuoCTC. P.J.P. designed and supervised the study, J. B., J.L.P, P.B., and P.J.P. collected the data, P.B. analyzed and interpreted the data and performed the statistical analyses, P.B. and P.J.P wrote the paper. 


\section{References}

1. Kim DH, Pickhardt PJ, Taylor AJ, Leung WK, Winter TC, Hinshaw JL, Gopal DV, Reichelderfer M, Hsu RH, Pfau PR. CT colonography versus colonoscopy for the detection of advanced neoplasia. New England Journal of Medicine. 2007; 357 (14):1403-1412. [PubMed: 17914041]

2. Pickhardt PJ, Hassan C, Laghi A, Zullo A, Kim DH, Morini S. Cost-effectiveness of colorectal cancer screening with computed tomography colonography - The impact of not reporting diminutive lesions. Cancer. 2007; 109 (11):2213-2221. [PubMed: 17455218]

3. Hassan C, Pickhardt P, Laghi A, Kim D, Zullo A, Iafrate F, Di Giulio L, Morini S. Computed tomographic colonography to screen for colorectal cancer, extracolonic cancer, and aortic aneurysm. Arch Intern Med. 2008; 168 (7):696-705. [PubMed: 18413551]

4. Pickhardt PJ, Choi JR, Hwang I, Butler JA, Puckett ML, Hildebrandt HA, Wong RK, Nugent PA, Mysliwiec PA, Schindler WR. Computed tomographic virtual colonoscopy to screen for colorectal neoplasia in asymptomatic adults. New England Journal of Medicine. 2003; 349 (23):2191-2200. [PubMed: 14657426]

5. Johnson CD, Chen MH, Toledano AY, Heiken JP, Dachman A, Kuo MD, Menias CO, Siewert B, Cheema JI, Obregon RG, Fidler JL, Zimmerman P, Horton KM, Coakley K, Iyer RB, Hara AK, Halvorsen RA, Casola G, Yee J, Herman BA, Burgart LJ, Limburg PJ. Accuracy of CT colonography for detection of large adenomas and cancers. New England Journal of Medicine. 2008; 359 (12):1207-1217. [PubMed: 18799557]

6. Seeff LC, Manninen DL, Dong FB, Chattopadhyay SK, Nadel MR, Tangka FKL, Molinari NAM. Is there endoscopic capacity to provide colorectal cancer screening to the unscreened population in the United States? Gastroenterology. 2004; 127 (6):1661-1669. [PubMed: 15578502]

7. Schwartz DC, Dasher KJ, Said A, Gopal DV, Reichelderfer M, Kim DH, Pickhardt PJ, Taylor AJ, Pfau PR. Impact of a CT colonography screening program on endoscopic colonoscopy in clinical practice. American Journal of Gastroenterology. 2008; 103:346-351.10.1111/j. 1572-0241.2007.01586.x [PubMed: 17941961]

8. Pickhardt PJ. Computed tomography colonography: emerging evidence to further support clinical effectiveness. Current Opinion in Gastroenterology. 2013; 29 (1):55-59.10.1097/MOG. 0b013e32835a3480 [PubMed: 23044493]

9. Shapiro JA, Seeff LC, Thompson TD, Nadel MR, Klabunde CN, Vernon SW. Colorectal cancer test use from the 2005 National Health Interview Survey. Cancer Epidemiol Biomarkers Prev. 2008; 17 (7):1623-1630.10.1158/1055-9965.EPI-07-2838 [PubMed: 18628413]

10. Force USPST . Screening for colorectal cancer: U.S. Preventive Services Task Force recommendation statement. Ann Intern Med. 2008; 149 (9):627-637. [PubMed: 18838716]

11. Maciosek MV, Solberg LI, Coffield AB, Edwards NM, Goodman MJ. Colorectal cancer screening: health impact and cost effectiveness. Am J Prev Med. 2006; 31 (1):80-89.10.1016/j.amepre. 2006.03.009 [PubMed: 16777546]

12. Harewood GC, Wiersema MJ, Melton LJ 3rd. A prospective, controlled assessment of factors influencing acceptance of screening colonoscopy. Am J Gastroenterol. 2002; 97 (12):31863194.10.1111/j.1572-0241.2002.07129.x [PubMed: 12492209]

13. Beebe TJ, Johnson CD, Stoner SM, Anderson KJ, Limburg PJ. Assessing attitudes toward laxative preparation in colorectal cancer screening and effects on future testing: potential receptivity to computed tomographic colonography. Mayo Clin Proc. 2007; 82 (6):666-671.10.4065/82.6.666 [PubMed: 17550745]

14. Pickhardt PJ. Colonic preparation for computed tomographic colonography: Understanding the relative advantages and disadvantages of a noncathartic approach. Mayo Clinic Proceedings. 2007; 82 (6):659-661. [PubMed: 17550742]

15. Pickhardt, PJ.; Kim, DH. CT colonography: principles and practice of virtual colonoscopy. Saunders, Philadelphia: 2010.

16. Kim DH, Pickhardt PJ, Hinshaw JL, Taylor AJ, Mukherjee R, Pfau PR. Prospective blinded trial comparing 45-mL and 90-mL doses of oral sodium phosphate for bowel preparation before computed tomographic colonography. Journal of Computer Assisted Tomography. 2007; 31 (1): 53-58. [PubMed: 17259833] 
17. Berkelhammer C, Ekambaram A, Silva RG. Low-volume oral colonoscopy bowel preparation: sodium phosphate and magnesium citrate. Gastrointest Endosc. 2002; 56 (1):89-94. [PubMed: 12085041]

18. Markowitz GS, Stokes MB, Radhakrishnan J, D'Agati VD. Acute phosphate nephropathy following oral sodium phosphate bowel purgative: An underrecognized cause of chronic renal failure. J Am Soc Nephrol. 2005; 16 (11):3389-3396. [PubMed: 16192415]

19. Borden ZS, Pickhardt PJ, Kim DH, Lubner MG, Agriantonis DJ, Hinshaw JL. Bowel Preparation for CT Colonography: Blinded Comparison of Magnesium Citrate and Sodium Phosphate for Catharsis. Radiology. 2010; 254 (1):138-144. [PubMed: 20032148]

20. Macari M, Lavelle M, Pedrosa I, Milano A, Dicker M, Megibow AJ, Xue XN. Effect of different bowel preparations on residual fluid at CT colonography. Radiology. 2001; 218 (1):274-277. [PubMed: 11152814]

21. Vanner SJ, MacDonald PH, Paterson WG, Prentice RS, Da Costa LR, Beck IT. A randomized prospective trial comparing oral sodium phosphate with standard polyethylene glycol-based lavage solution (Golytely) in the preparation of patients for colonoscopy. Am J Gastroenterol. 1990; 85 (4):422-427. [PubMed: 2183591]

22. Di Palma JA, Rodriguez R, McGowan J, Cleveland M. A randomized clinical study evaluating the safety and efficacy of a new, reduced-volume, oral sulfate colon-cleansing preparation for colonoscopy. Am J Gastroenterol. 2009; 104 (9):2275-2284.10.1038/ajg.2009.389 [PubMed: 19584830]

23. Rex DK, Di Palma JA, Rodriguez R, McGowan J, Cleveland M. A randomized clinical study comparing reduced-volume oral sulfate solution with standard 4-liter sulfate-free electrolyte lavage solution as preparation for colonoscopy. Gastrointest Endosc. 2010; 72 (2):328336.10.1016/j.gie.2010.03.1054 [PubMed: 20646695]

24. Cohen SM, Wexner SD, Binderow SR, Nogueras JJ, Daniel N, Ehrenpreis ED, Jensen J, Bonner GF, Ruderman WB. Prospective, randomized, endoscopic-blinded trial comparing precolonoscopy bowel cleansing methods. Dis Colon Rectum. 1994; 37 (7):689-696. [PubMed: 8026236]

25. Pickhardt PJ. Screening CT colonography: how I do it. AJR Am J Roentgenol. 2007; 189 (2):290298. [PubMed: 17646453]

26. Pickhardt PJ, Choi JHR. Electronic cleansing and stool tagging in CT colonography: Advantages and pitfalls with primary three-dimensional evaluation. American Journal of Roentgenology. 2003; 181 (3):799-805. [PubMed: 12933484]

27. Slater A, Taylor SA, Burling D, Gartner L, Scarth J, Halligan S. Colonic polyps: effect of attenuation of tagged fluid and viewing window on conspicuity and measurement--in vitro experiment with porcine colonic specimen. Radiology. 2006; 240 (1):101-109.10.1148/radiol. 2401050984 [PubMed: 16793973]

28. Deshpande KK, Summers RM, Van Uitert RL, Franaszek M, Brown L, Dwyer AJ, Fletcher JG, Choi JR, Pickhardt PJ. Quality assessment for CT colonography: Validation of automated measurement of colonic distention and residual fluid. American Journal of Roentgenology. 2007; 189 (6):1457-1463. [PubMed: 18029885]

29. Van Uitert RL, Summers RM, White JM, Deshpande KK, Choi JR, Pickhardt PJ. Temporal and multiinstitutional quality assessment of CT colonography. AJR Am J Roentgenol. 2008; 191 (5): 1503-1508. [PubMed: 18941092]

30. Hung PW, Paik DS, Napel S, Yee J, Jeffrey RB, Steinauer-Gebauer A, Min J, Jathavedam A, Beaulieu CF. Quantification of distention in CT colonography: Development and validation of three computer algorithms. Radiology. 2002; 222 (2):543-554.10.1148/radiol.2222010600 [PubMed: 11818626]

31. Park SH, Ha HK, Kim MJ, Kim KW, Kim AY, Yang DH, Lee MG, Kim PN, Shin YM, Yang SK, Myung SJ, Min YI. False-negative results at multi-detector row CT colonography: Multivariate analysis of causes for missed lesions. Radiology. 2005; 235 (2):495-502. [PubMed: 15770042]

32. Pickhardt PJ, Kim DH. CT Colonography: Pitfalls in Interpretation. Radiologic Clinics of North America. 2013; 51 (1):69-88.10.1016/j.rcl.2012.09.005 [PubMed: 23182508] 


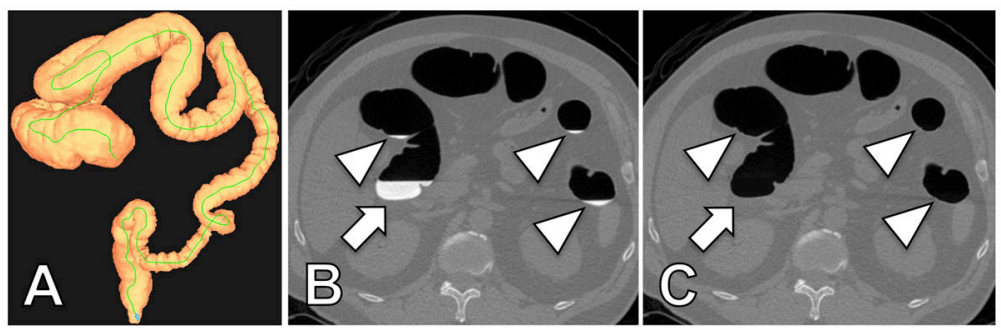

Figure 1.

CTC examination with automated quantification of residual colonic fluid volume and attenuation in a 57-year-old man. (A) Three-dimensional display map of the correctly segmented colon. The automated volumetric CTC tool allows accurate quantification of the amount and attenuation of the total residual colonic fluid. Automatically calculated total colonic residual fluid in this patient receiving novel OSS regimen was $73 \mathrm{ml}$. The automatically calculated attenuation of the residual fluid was $826 \mathrm{HU}$. Two-dimensional axial CTC images before $(\mathbf{B})$ and after $(\mathbf{C})$ automated digital subtraction of residual colonic fluid allow verification of correct segmentation. Note that not only large fluid collections (arrow) are captured but also smallest fluid residues (arrowheads). 

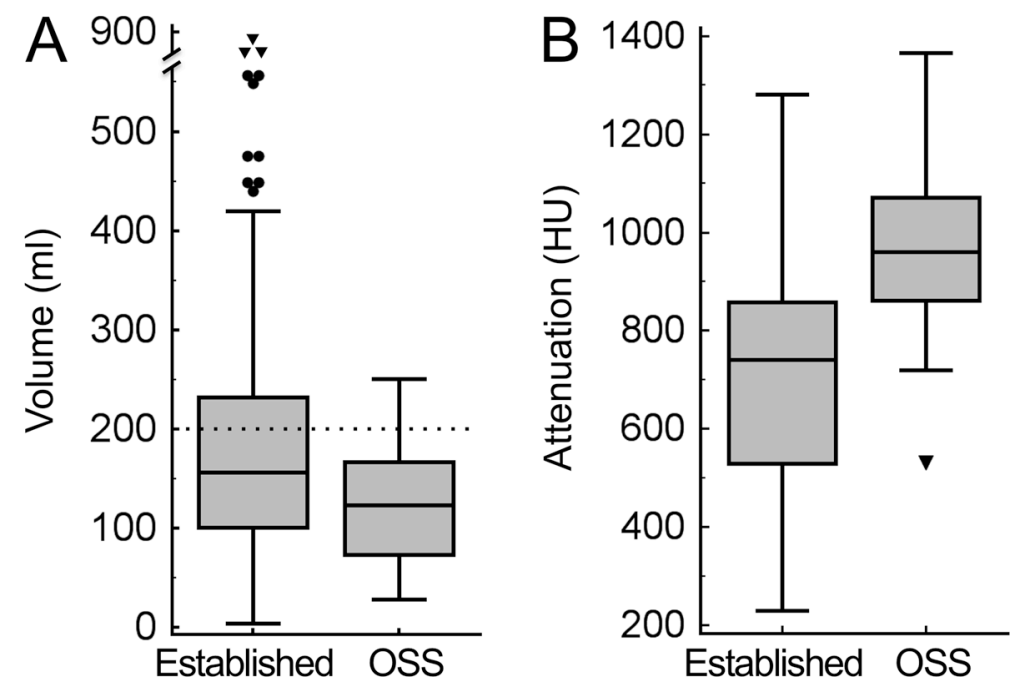

Figure 2.

Mean volume and attenuation of residual colonic fluid over all established cathartic agents versus OSS regimen as quantified by automated volumetric QA tool. (A) Bar graph shows mean residual colonic fluid volume. The fluid volume was significantly lower for OSS regimen $(125 \pm 60 \mathrm{ml})$ than for established cathartic agents (average of $2 \mathrm{xNaP}, \mathrm{MgC}, \mathrm{NaP}$ and PEG) $(180 \pm 121 \mathrm{ml})(\mathrm{p}<0.001)$. Note the outliers (dots) and extreme outliers (triangles) with high fluid volumes of up to $853 \mathrm{ml}$ when using established cathartic agents, which hamper 3D endoluminal fly-through without electronic cleansing. Dotted line indicates 200 $\mathrm{ml}$ threshold of total residual colonic fluid. (B) Bar graph shows the mean attenuation of the residual colonic fluid. The attenuation was significantly higher for the OSS regimen (956 $\pm 167 \mathrm{HU})$ as compared to the average of established cathartic agents $(692 \pm 223 \mathrm{HU})$ $(\mathrm{p}<0.0001)$. 


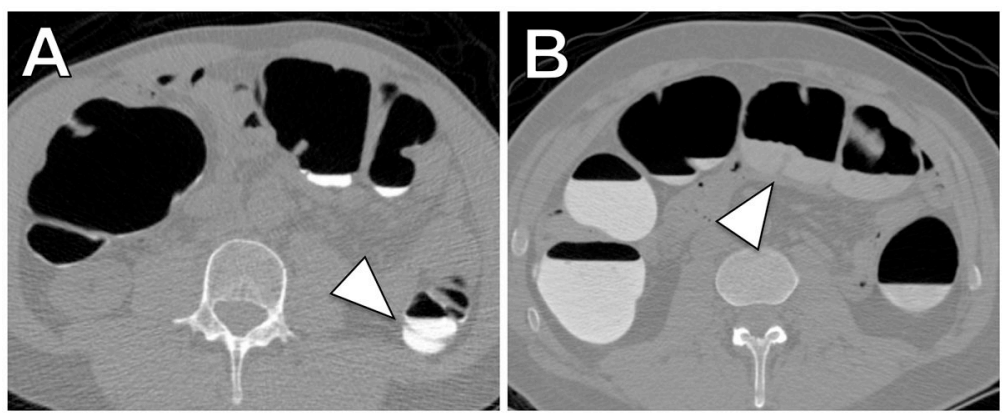

Figure 3.

CTC examinations in two patients receiving the new OSS regimen (A) and the established sodium phosphate regimen (B). (A) Axial two-dimensional CTC image from a 62-year-old man who underwent OSS regimen illustrates the calculated low total residual fluid volume $(89 \mathrm{ml})$ with high attenuation $(897 \mathrm{HU})$. (B) Axial two-dimensional CTC image from a 58year-old man who underwent sodium phosphate regimen illustrates the calculated high residual total fluid volume $(853 \mathrm{ml})$ with low attenuation $(440 \mathrm{HU})$. Note the good conspicuity of colonic fold against the high attenuation fluid after OSS regimen (A, arrow head) as compared to poor conspicuity of a fold against the low attenuation fluid after $\mathrm{MgC}$ regimen ( $\mathrm{B}$, arrowhead). Both cases also illustrate the inadequacy of the established manual fluid volume and attenuation quantification methods. In (A) the volume of descending colon occupied by fluid would be rated $>50 \%$, albeit this is not due to high fluid volume, but rather due to poor overall distension. In (B) the different attenuations of the fluid within the colon are clearly evident and indicate the sampling error of manual ROI-based methods for attenuation quantification. 

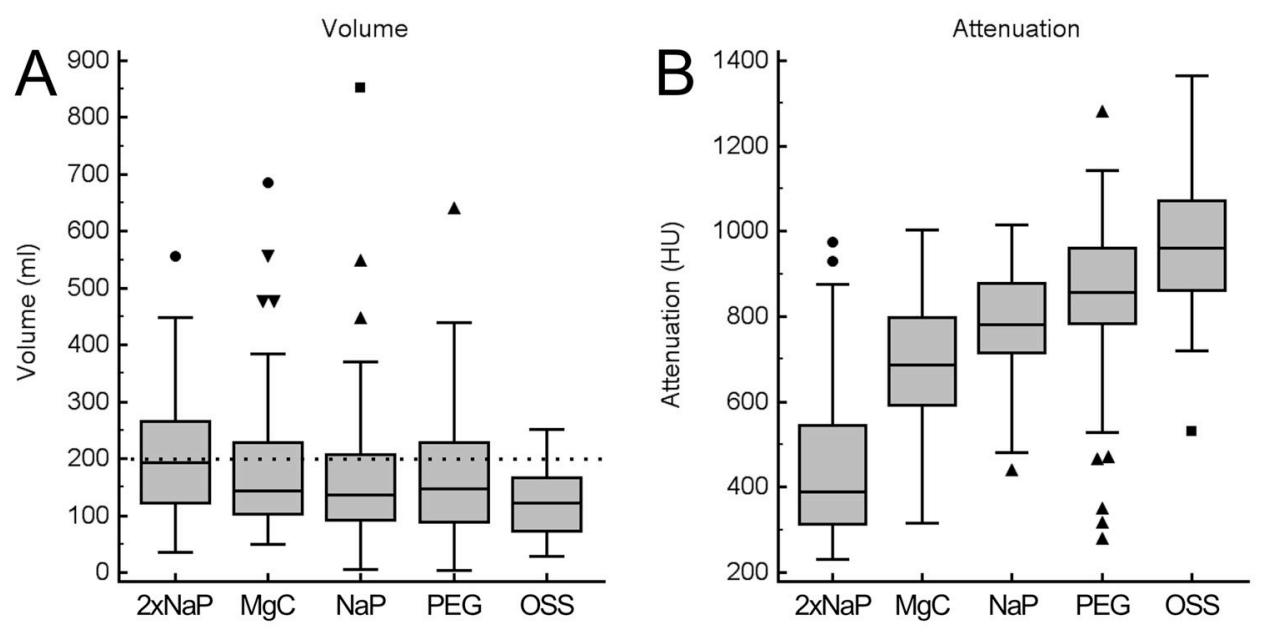

Figure 4.

Mean volume and attenuation of residual colonic fluid for each cathartic agent as quantified by automated volumetric QA tool. (A) Box and whisker plots showing mean residual colonic fluid volume. The mean residual volume was smallest when using the OSS regimen $(125 \pm 60 \mathrm{ml})$ and significantly higher using $2 \mathrm{xNaP}$ regimen $(206 \pm 125 \mathrm{ml})(\mathrm{p}<0.0001), \mathrm{MgC}$ regimen $(184 \pm 125 \mathrm{ml})(\mathrm{p}<0.01)$ and $\mathrm{PEG}$ regimen $(166 \pm 114 \mathrm{ml})(\mathrm{p}<0.05)$. NaP regimen showed also a higher residual volume $(165 \pm 135 \mathrm{ml})$ than OSS regimen but without reaching a statistically difference $(\mathrm{p}=0.067)$. Note the outliers with high residual volumes with established cathartic agents that are not observed with OSS. Dotted line indicates $200 \mathrm{ml}$ threshold of total residual colonic fluid. (B) Box and whisker plots showing the mean attenuation of the residual colonic fluid. The attenuation was significantly higher for the OSS regimen $(955 \pm 167 \mathrm{HU})$ as compared to all of the other established cathartic agents, ranging from $406 \pm 191 \mathrm{HU}$ for $2 \mathrm{xNaP}$ regimen $(\mathrm{p}<0.0001)$ to $843 \pm 193 \mathrm{HU}$ for PEG regimen $(\mathrm{p}=0.012)$. 


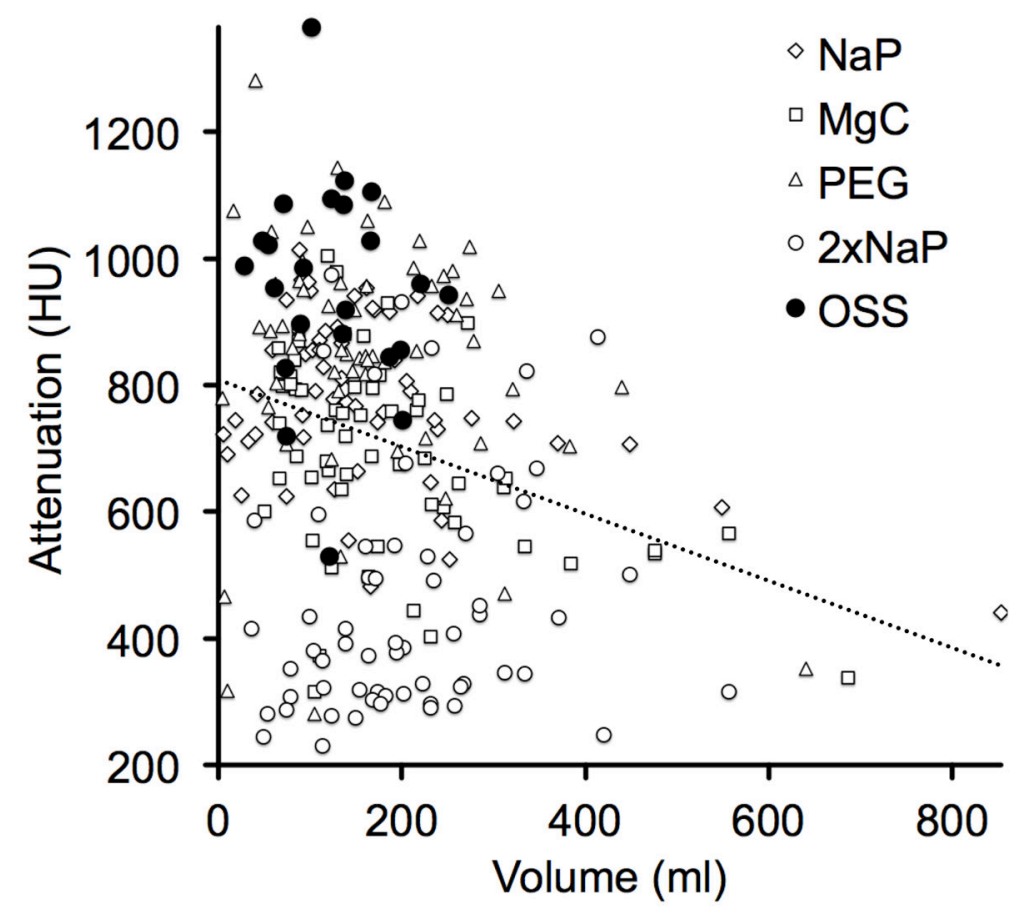

Figure 5.

Automated volumetric QA tool reveals inverse correlation between volume and attenuation of residual colonic fluid. Graph depicts residual fluid attenuation plotted against the fluid volume across all different cathartic agents. As residual fluid volume increases, the degree of fluid attenuation decreases. Correlation is $r=-0.262(\mathrm{p}<0.0001)$. OSS regimen generally yielded low residual volume with high attenuation (filled dots). 


\section{Table 1}

Patient Demographic Information according to Preparation Group

\begin{tabular}{lll} 
Regimen & Mean Age $^{*}$ & Men/Women \\
\hline 2xNaP & $58.3(46-75)$ & $39 / 21$ \\
$\mathrm{MgC}$ & $62.1(55-78)$ & $32 / 28$ \\
$\mathrm{NaP}$ & $55.4(45-67)$ & $26 / 34$ \\
$\mathrm{PEG}$ & $65.1(46-93)$ & $29 / 31$ \\
$\mathrm{OSS}$ & $59.2(53-66)$ & $11 / 12$ \\
\hline
\end{tabular}

Numbers in parenthesis are ranges. 